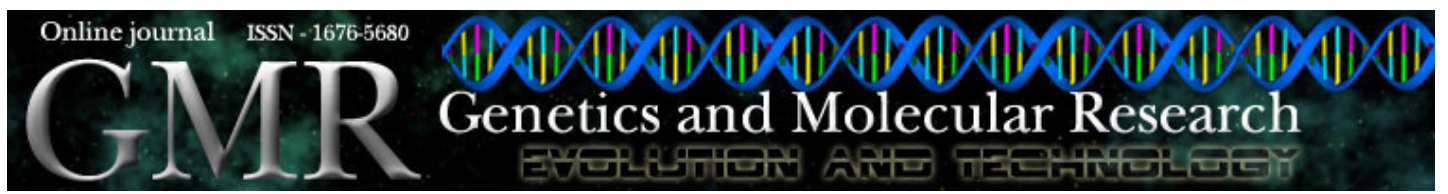

\title{
Detection of stabilizing selection in favor of the Santa Cruz homokaryotype in Drosophila pseudoobscura populations from the high plateau of the Colombian Andes
}

\author{
Diana Alvarez, Manuel Ruiz-Garcia, Jimena Guerrero and \\ Juan P. Jaramillo \\ Unidad de Genetica (Genetica de Poblaciones-Biologia Evolutiva), Depar- \\ tamento de Biologia, Facultad de Ciencias, Pontificia Universidad Javeriana, \\ Cra 7a No. 43 82. Bogota dc., Colombia \\ Corresponding author: M. Ruiz-Garcia \\ E-mail:mruiz@javercol.javeriana.edu.co \\ Genet. Mol. Res. 1 (1): 01-24 (2002) \\ Received February 8, 2002 \\ Published February 28, 2002
}

\begin{abstract}
Chromosome 3 rearrangements were studied in five Drosophila pseudoobscura populations from the high plateau of the Colombian Andes. As in previous studies, the Santa Cruz and Tree Line rearrangements were predominant in these populations, but for the first time other rearrangements such as the Olympic, Cuernavaca and a rearrangement similar to the endemic Mexican Amecameca rearrangement were also discovered. Researchers in the early 1960's showed that Colombian D. pseudoobscura populations were not in accordance with Carson's theory. They found a special heterotic system in this geographically isolated population. Our current results do not support these findings but instead favor Carson's theory, because in practically all the populations studied the homokaryotype excess was close to fixation. These new results indicate that some stabilizing selective pressures in favor of the homokaryotypes (especially Santa Cruz) have appeared in the Colombian plateau during the last 10-12 years. These new changes may be related to deforestation and habitat destruction by human beings and/or climatic changes motivated by the El Niño phenomenon. Genetic heterogeneity between populations was not significant and there was no isolation-by-distance between them, findings which are contrary to those observed in some North American populations and which show that the Colombian populations now have rigid genetic systems. The frequency of the Santa Cruz rearrangement
\end{abstract}


was also found to have increased in some populations over the last few years.

Key words: Drosophila pseudoobscura, Colombia, Chromosomal polymorphism, Selection in favor of homokaryotypes, Changes in rearrangement frequencies

\section{INTRODUCTION}

During the last 60 years, most of the essential concepts that have allowed the development of evolutionary biology and population genetics were obtained through studies on Drosophila pseudoobscura (Anderson et al.,1991; Popadic and Anderson, 1994; Popadic et al., 1995). In the 1930's and 40's, Dobzhansky et al. began an exhaustive study of the karyotype rearrangements of chromosome 3 of this insect in populations from southwestern USA and Mexico, with studies being carried out in California, Nevada, New Mexico, Texas and Colorado (Dobzhansky, 1937, 1939, 1943, 1971; Dobzhansky and Epling, 1944; Anderson et al., 1975; Dobzhansky et al., 1975) as well as in central Mexico (Olvera et al., 1979, 1985; Guzman et al., 1993; Levine et al., 1995). These regions are considered the central distribution range of this species, but there is also an apparently isolated Andean population discovered in the early 1960's by Dobzhansky et al. (1963), which is located in the South American Tropic on the Cundiboyacense plateau near the Colombian capital, Bogota.

This Andean Drosophila population has interested many evolutionary biologists because of its reproductive isolation due to its geographic distance from the central distribution range of D. pseudoobscura. The morphology and reproduction of this population have been studied by several workers (Prakash, 1972; Alvarez et al., 1989; Alvarez, 1993; Ruiz-Garcia and Alvarez, 1997a, 2000, 2001) and many differences with respect to North American populations have been found. The first molecular genetic studies were on allozyme levels (Prakash et al., 1969; Ayala and Dobzhansky, 1974; Singh et al., 1976; Coyne and Felton, 1977), and later directly on DNA (Aquadro et al., 1991; Schaeffer and Miller, 1991, 1992; Alvarez et al., 2001).

However, the first study carried out on the Andean population was made using chromosome 3 rearrangements (Dobzhansky et al., 1963), which reflect more historical information on lineage than the allelic mutations of later studies. This is because rearrangements are unique events that are highly unlikely to be repeated twice, so that if two populations have the same rearrangement they are most probably co-ancestral (Olvera et al., 1979; Guzman et al., 1993).

The results of the 1963 study by Dobzhansky et al. were unexpected, because only the Santa Cruz (SC) and Tree Line (TL) rearrangements were present at frequencies different from those found in North American or Mexican populations, where more than 40 rearrangements have been described. This suggests that a founder effect event may have occurred in Colombia, arising from a population with a chromosome 3 constitution similar to Guatemalan populations (Mayhew et al., 1966), where Cuernavaca (CU), Oaxaca (OA), SC and TL rearrangements are present. The environmental and ecological conditions (temperature, rainfall, seasons, microand macroflora) in tropical Colombia are very different from those found in the central distribution range of $D$. pseudoobscura, and it can be expected that in these circumstances there would be radical genetic reconstruction modifying diverse genetic parameters, including the type of chromosomal rearrangements present and their frequencies (Dobzhansky et al., 1963). These authors also found a heterokaryotype (SC/TL) excess that clearly showed an heterotic effect, where SC/SC and TL/TL homokaryotypes were less adaptable than the 
heterokaryotypes, a phenomenon also reported in several North American D. pseudoobscura populations belonging to various different chromosomal rearrangement groups. These results apparently contradict Carson's theory (Carson, 1955, 1956, 1959, 1965), which states that heterosis, a high number of polymorphisms, low recombination rates and general adaptability occur in central range populations that facilitate their survival under varied ecological conditions, while geographically, or ecologically, marginal populations should show homoselection, loss of genic variability, genetic drift, high recombination rates and adaptive specialization. However, Dobzhansky et al. (1963) paradoxically found loss of variability and heterosis (instead of homoselection) in the Colombian populations that they studied, leading them to sustain that the Colombian populations had developed a special heterotic system with a high degree of specialization.

Using Colombian samples from the same years as the Dobzhansky et al. (1963) study and Guatemalan samples from 1961 and 1962, Mayhew et al. (1966) also showed that heterokaryotypes were overrepresented in both populations. Cárdenas (1988) studied a large number of D. pseudoobscura samples from Colombian plateau populations and found the same previously reported rearrangements, with only the SC (64.2\%) and TL (35.8\%) rearrangements. In the present study, however, $67 \%$ of the samples from wild female isolines and $92 \%$ of wild male samples were in Hardy-Weinberg equilibrium while most of those which were not in equilibrium had heterokaryotype excess or a randomly distributed deficit. The SC and TL rearrangement frequencies were similar to those previously reported in 1963 by Dobzhansky et al. $(\mathrm{SC}=65.6 \%, \mathrm{TL}=34.4 \%)$ and in 1966 by Mayhew et al. $(\mathrm{SC}=62.7 \%, \mathrm{TL}=37.3 \%)$. In all these studies, it was affirmed that the species occurred frequently in Colombian populations. Dobzhansky et al. (1963) stated that "we are in an island in the central region of the Eastern Andes, but inside this island, the species is locally common, forming between 1 and $55 \%$ of the total Drosophila species captured", a finding confirmed by Cárdenas (1988).

In 1996 and 1997 when our group sampled this species in different parts of the Colombian plateau near Bogota D. pseudoobscura was difficult to find, suggesting that this species is less frequent now than previously. It is possible that different selective and stochastic evolutionary factors could be affecting not only the abundance of this species but also chromosomal rearrangements in this isolated population, and a new study on these rearrangements may shed some light on the divergent data reported by the authors cited above. This was one of the aims of the study reported in this paper, but we also wanted to determine whether or not the obvious differences in habitat, ecological and climatic conditions between the Colombian and the central range (North American and Mexican) populations had produced any significant differences in the genetic structure of chromosome 3 rearrangements among both types of populations.

\section{There are some other relevant questions}

Firstly, is there any significant genetic heterogeneity in chromosome 3 rearrangements at a micro-geographical level in Colombian populations? In some North American and Mexican populations differences have been detected in the frequency of chromosomal rearrangements at a micro-geographical level. Studies by Dobzhansky and Queal (1938) on 11 populations separated by $96 \mathrm{~km}$ and Koller (1939) on populations separated by $11 \mathrm{~km}$ have shown that there was high genetic heterogeneity between populations, while Dobzhansky (1939) sampling Texan populations separated by only $2.5 \mathrm{~km}$, again found significant heterogeneity. Levine et al. (1995) presented data on two Mexican populations (Amecameca and Tulancingo) sampled 
with traps placed every $3.5 \mathrm{~m}$ and found that for the most frequent rearrangement (CU) there was significant heterogeneity in the Amecameca population but not in the Tulancingo population.

Secondly, can any cyclic seasonal selective pressure be detected in Colombian populations similar to the pressures reported in North American and Mexican populations that have been associated with systematic seasonal changes in chromosomal rearrangement frequencies? Dobzhansky $(1943,1947 \mathrm{a}, \mathrm{b})$ found that natural selection was present in at least two of three St. Jacinto (California) populations that he examined, because of seasonal changes in chromosomal rearrangements. Similar cyclic changes have also been recorded for $D$. funebris populations (Dubinin and Tiniakov, 1945, 1946) and other Drosophila species (Dobzhansky et al., 1964; Epling et al., 1957). These changes cannot have been caused by genetic drift, because they were cyclic and followed the seasonal changes every year. In Pinon Flats and Andreas Canyon for example, there were two large demographic maximums in a year, one in early spring and the other in autumn, exactly when the standard (ST) frequencies were highest. In the hotter months (late spring/early summer) there was a demographic depression with an increase in the frequencies of Arrowhead (AR) and Chiricaua $(\mathrm{CH})$ rearrangements. A similar situation was detected in Mexico (Amecameca population) involving the CU and TL rearrangements, with the CU arrangement being more frequent in spring and autumn and the TL in summer. In Californian populations Levine et al. (1995) found no important seasonal changes in the TL rearrangement, although the frequency of variations is generally lower in Mexican than in many of the reported Californian populations. Powell (1992) has reported that other Californian and North American populations do not show these annual cyclic changes. At Keen Camp, 15 miles from the populations referred to above and with a different rainfall level, there were no seasonal variations (Dobzhansky, 1943, 1947b; Epling et al., 1957). Crumpacker and Williams (1974) studied two populations in north and south of Denver (Colorado), and found that in the northern population rearrangement frequencies were constant during the year, while in the southern population although the overall frequencies were similar to the northern population they had seasonal cycles, with the AR rearrangement reaching high values in spring and early summer but declining to its lowest frequency at the end of summer, reaching a new maximum in autumn. These observations have led us to formulate the following questions: Do the Colombian populations have a flexible genetic system like many of the American populations or do they have a rigid system? What kind of selection, if any, is present in the Colombian populations?

Thirdly, which selective agents are acting on Colombian populations? Are such agents the same as those affecting North American populations and can stochastic processes be detected in these populations? Although the studies on D. pseudoobscura chromosome 3 rearrangements were initiated in the 1930's the agent, or agents, responsible for the changes observed in wild populations of this species have not yet been determined. Many possible selective agents have been studied by several workers, including temperature (Dobzhansky, 1943; Landgridge, 1962, 1968; Druger, 1966; Parsons, 1971), the levels of rainfall and snow (Dobzhansky, 1947b), altitude (Dobzhansky, 1943, 1948), aridity (Strickberger and Wills, 1966), competition and density of larvae (Birch, 1955), viability dependent on the coexisting genotypes at a determined site (Levene et al., 1954, 1958; Lewontin, 1958; Battaglia and Smith, 1962; Anderson et al., 1975), frequency-dependent selection (Kojima and Yarbrough, 1967), contamination by insecticides (Dobzhansky, 1958, 1971; Anderson et al., 1968), and the differential fitness of each rearrangement to yeast and bacteria (Brito da Cunha, 1951), but none of them have been conclusively demonstrated to be selective agents. For instance, Dobzhansky (1962) reported that D. pseudoobscura populations from the Chiricaua mountains in Arizona had constant AR and $\mathrm{CH}$ frequencies, even though the environmental conditions varied from the Sonoran desert 
at an altitude of 3900 feet to conifer forests with high rainfall levels at 8900 feet.

Answers to these questions could show the differences in selective pressures that a species like D. pseudoobscura faces on a tropical plateau compared to those encountered in septentrional regions of North America.

\section{MATERIAL AND METHODS}

\section{Populations and sampling procedures}

D. pseudoobscura chromosomal rearrangement frequencies were analyzed in five Colombian populations (Table 1, Figure 1). All the populations were located in the Colombian department of Cundimarca, bio-climatically classified as a "cold" thermal-ground and Tropical alpine (Paramo) region (Bernal, 1989). Three of these populations (Potosi, Torobarroso and Santillana) were also analyzed by Cárdenas (1988), which allowed us to make temporal comparisons.

Table 1. Collection site data for Drosophila pseudoobscura populations.

\begin{tabular}{lcccccc} 
Collection site & \multicolumn{2}{c}{$\begin{array}{c}\text { Altitude above } \\
\text { sea level }\end{array}$} & & \multicolumn{2}{c}{$\begin{array}{c}\text { Average } \\
\text { temperature }\end{array}$} & \multirow{2}{*}{$\begin{array}{c}\text { Average annual } \\
\text { precipitation millimeters }\end{array}$} \\
\cline { 2 - 3 } & meters & feet & & ${ }^{\circ} \mathrm{C}$ & ${ }^{\circ} \mathrm{F}$ & \\
\hline Torobarroso (Cajicá) & 2600 & 8500 & & 13.9 & 57.02 & 742 \\
Potosi (La Calera) & 2850 & 9300 & & 12.7 & 54.86 & 1200 \\
Santillana (Sopó) & 2650 & 8700 & & 13.8 & 57 & 793 \\
Susa & 2580 & 8500 & & 14 & 57.2 & NA* $^{*}$ \\
Sutatausa & 2600 & 8500 & & 13 & 55.4 & 800 \\
\hline
\end{tabular}

*Not Available

Figure 1. Geographical location of the five Drosophila pseudoobscura populations sampled in the Colombian high plateau.

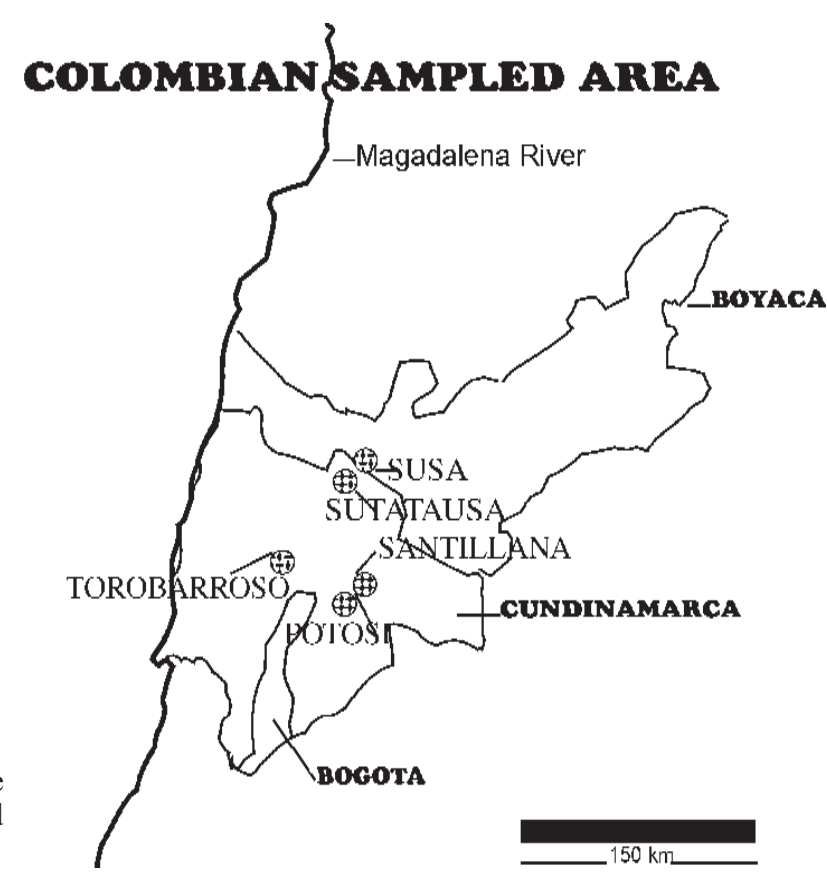

Genetics and Molecular Research 1 (1): 01-24 (2002) www.funpecrp.com.br 
The flies were collected each month for a year, using "banana-traps" in dishes with drainage holes and protected with a net to prevent other animals from eating the fruit. Once collected, the insects were taken to the lab, where males and females were separated and isolines established with the fecundated females, the wild-type males being crossed with homokaryotypic (SC/SC) virgin females. For karyotypic studies the salivary glands of third-stage larvae were dissected out, stained with orcein for $20 \mathrm{~min}$, squash-mounted and the polytenic chromosomes observed under a microscope (Ashburner, 1989).

\section{Data analysis}

Once the rearrangements were identified and the homo- and heterokaryotype frequencies obtained, Wright's F-statistics were applied using the Weir and Cockerham method (1984), assuming that the sample came from a single population formed by the five subpopulations shown in Table 1. The $\mathrm{F}_{\mathrm{IT}}$ and $\mathrm{F}_{\mathrm{IS}}$ statistics allow us to determine the presence of Hardy-Weinberg $(\mathrm{H}-\mathrm{W})$ equilibrium in the total population, and on average in each subpopulation analyzed (Nei, 1977). The $\mathrm{F}_{\mathrm{ST}}$ statistic gives us the degree of genetic heterogeneity between the subpopulations, each of which was individually analyzed for H-W equilibrium using the Wright's (1965) F-statistic and the Robertson and Hill's (1984) f-statistic.

Wright's F-statistic was calculated as $\mathrm{F}=1-\left(\mathrm{H}_{\mathrm{o}} / \mathrm{H}_{\mathrm{e}}\right)$, where $\mathrm{H}_{\mathrm{o}}$ is the number of observed heterokaryotypes and $\mathrm{H}_{\mathrm{e}}$ the number of heterokaryotypes expected under $\mathrm{H}-\mathrm{W}$ equilibrium. The chi-squared $\left(\chi^{2}\right)$ test can be used to test for deviation of the F-statistic from zero using the relationship $\chi^{2}=\mathrm{F}^{2} \mathrm{~N}(\mathrm{~m}-1)$ with $\mathrm{m}(\mathrm{m}-1) / 2$ degrees of freedom, where $N$ is the sample size and $m$ the number of chromosome 3 rearrangements (Li and Horvitz, 1953). Rasmussen's (1964) method was used to measure F-variance. The second statistic (f) is an unbiased estimator based on the proportion of homokaryotypic rearrangements. For each rearrangement the unbiased estimate of a homokaryotypic frequency (ii) deviation, with respect to the expected $\mathrm{H}-\mathrm{W}$ value is: $\mathrm{T}_{\mathrm{ii}}=\left[2(2 \mathrm{n}-1) \mathrm{n}_{\mathrm{ii}}-\mathrm{n}_{\mathrm{i}}\left(\mathrm{n}_{\mathrm{I}}-1\right)\right] /[4(\mathrm{n}-1)]$, where $n$ is the sample size, $\mathrm{n}_{\mathrm{ii}}$ is the number of observed homokaryotypes, and $n_{i}$ the number of $i$ rearrangements in the sample. For each rearrangement the f-estimation is expressed as $\mathrm{f}_{\mathrm{ii}}=4 \mathrm{n} \mathrm{T}_{\mathrm{ii}} /\left(\mathrm{n}_{\mathrm{i}}\left(2 \mathrm{n}-\mathrm{n}_{\mathrm{i}}\right)\right)$. The estimates obtained in each $i$ rearrangement were used to obtain a global chromosome 3 statistic, weighting $\mathrm{f}_{\mathrm{ii}}$ with $\left(1-\mathrm{p}_{\mathrm{i}}\right)$, where $p_{i}$ is the rearrangement frequency in a given population. The $f_{T}$ total statistic was calculated as $\mathrm{f}_{\mathrm{T}}=2\left(\mathrm{~T}_{\mathrm{ii}} / \mathrm{n}_{\mathrm{i}}\right) /(\mathrm{m}-1)$, where $m$ is the number of chromosome 3 rearrangements. The variances of the $f_{i i}$ estimate for each rearrangement, and of the $f_{T}$ estimate for chromosome 3 were, respectively, $\operatorname{Var}\left(\mathrm{f}_{\mathrm{ii}}\right)=1 / \mathrm{n}$ and $\operatorname{Var}\left(\mathrm{f}_{\mathrm{T}}\right)=1 /[\mathrm{n}(\mathrm{m}-1)]$. To test the statistical significance of the three Wright's F-statistics $\left(\mathrm{F}_{\mathrm{IT}}, \mathrm{F}_{\mathrm{IS}}\right.$ and $\mathrm{F}_{\mathrm{ST}}$ ), 500 Jackknife permutations were used (Efron, 1982) to recalculate the F-values and generate variance values, and 95 and $99 \%$ confidence intervals.

A factorial correspondence analysis was made to determine the relationships between populations and the chromosomal variables studied. To establish the differences between populations and the chromosomal rearrangements, the $\chi^{2}$ distance was used, this being the distance between two data columns $(i$ and $\mathrm{j})$ according to $\mathrm{d}_{\mathrm{ij}}=\left(\sum_{\mathrm{n}}\left(\left(\mathrm{f}_{\mathrm{ni}} / \mathrm{f}_{\mathrm{j}}\right)-\left(\mathrm{f}_{\mathrm{nj}} / \mathrm{f}_{\mathrm{j} . \mathrm{j}}\right)\right) / \mathrm{f}_{\mathrm{n}}\right)^{1 / 2}$, where $n$ is the number of columns considered (SC/SC, SC/TL and TL/TL), $\mathrm{f}_{\mathrm{ni}}$ and $\mathrm{f}_{\mathrm{nj}}$ are the relative frequencies of the $i t h$ and $j$ th columns with respect to the other columns, $\mathrm{f}_{\mathrm{fi}}$ and $\mathrm{f}_{\mathrm{.j}}$ are the relative frequencies of the $i$ th and $j$ th columns, respectively, and $\mathrm{f}_{\mathrm{n} .}$ is the relative frequency of each column when the rows (populations) are fixed. In this analysis, the data were adjusted according to $f_{i j}=\left(f_{i, j} f^{1 / 2}\left(1+\sum_{n}\left(I_{n}\right)^{1 / 2} Y_{\text {in }} f_{j n}\right)\right.$, where $f_{i j}$ are the relative observed frequencies, $f_{j .}$ is the relative frequency of the rows (populations), $\mathrm{I}_{\mathrm{n}}$ is the $n$th eigenvalue, and $\mathrm{Y}_{\text {in }}$ and $\mathrm{f}_{\mathrm{jn}}$ are the 
file and column elements in the factor matrix.

The factors would show whether or not there was independence between rows (populations) and columns (genotype rearrangements); if there was rearrangement the eigenvalues should be $=0$. For the graphic representation of column and row variables, coordinate matrices were obtained from the factor matrix. In addition, the absolute contribution matrices and the squared correlation matrices for column and row factors were calculated. The absolute contribution matrices allowed us to determine which variables contributed a high proportion to the variance attributable to each factor, while the squared correlation matrices allowed us to determine on which factor a variable had more influence.

To determine the relationship between the five populations by using rearrangement frequencies, two genetic distance methods were applied, Nei's (1972) and Prevosti's (1974). Prevosti's method was designed to study differences between operational taxonomic units (OTUs) based on chromosomal rearrangements (Prevosti et al., 1975). To establish whether or not two populations were genetically related we used the Rice and O' Brien (1980) and RuizGarcia (1994) criteria, which state that two populations are genetically related when Nei's genetic distance values are below $0.020(\mathrm{D}<0.020)$.

To generate dendrograms from the distance matrices, two algorithms were applied: the UPGMA (Sokal and Michener, 1958) and WPGMC (Lance and Williams, 1967) methods. The UPGMA method is most widely used, and in this method it is assumed that the length of a branch from the divergence point of each population is the same. The WPGMC method does not give equal weighting to each OTU, but finds the center of a cluster of OTUs in D-space and measures the dissimilarity of each OTU with regard to this point.

The non-parametric Mantel test (Mantel, 1967), normalized using the Smouse et al. (1986) technique, was used to detect possible relationships between the genetic and geographic distance matrices. Significance was measured with a Monte Carlo simulation with 2000 permutations, and an approximated Mantel's $t$-test (Mantel, 1967). The aerial distances method and the "greatcircle" method (Sphuler, 1972) were used to calculate the geographic distance matrices between population pairs.

\section{RESULTS}

Although there are more than 40 rearrangements described for D. pseudoobscura chromosome 3 (Guzman et al., 1994), only two high frequency rearrangements, the Santa Cruz (SC) and Tree Line (TL) rearrangements, have been found in the Colombian plateau. Tables 2 and 3 show the frequencies of homo- and heterokaryotypes detected in each population along

Table 2. Number of isolines, total number of larvae and chromosomes analyzed and the frequencies of homo- and heterokaryotypes of the Santa Cruz (SC) and Tree Line (TL) rearrangements in five Colombian populations.

\begin{tabular}{|c|c|c|c|c|c|c|}
\hline Populations & $\begin{array}{l}\text { Number of } \\
\text { isolines }\end{array}$ & $\mathrm{SC} / \mathrm{SC}$ & $\begin{array}{l}\text { Karyotype } \\
\text { frequency } \\
\text { SC/TL }\end{array}$ & TL/TL & $\begin{array}{l}\text { Total number of } \\
\text { larvae analyzed }\end{array}$ & $\begin{array}{l}\text { Total number of } \\
\text { chromosomes } \\
\text { analyzed }\end{array}$ \\
\hline Torobarroso & 17 & 98 & 2 & 39 & 139 & 278 \\
\hline Susa & 18 & 107 & 1 & 41 & 149 & 298 \\
\hline Sutatausa & 20 & 103 & 1 & 47 & 151 & 302 \\
\hline Potosi & 24 & 175 & 5 & 47 & 227 & 454 \\
\hline Santillana & 17 & 113 & 4 & 53 & 170 & 340 \\
\hline Total & 96 & 596 & 13 & 227 & 836 & 1672 \\
\hline
\end{tabular}

Genetics and Molecular Research 1 (1): 01-24 (2002) www.funpecrp.com.br 
Table 3. Santa Cruz (SC) and Tree Line (TL) rearrangement frequencies and standard deviations in five Colombian Drosophila pseudoobscura populations.

\begin{tabular}{lcc} 
Populations & \multicolumn{2}{c}{ Frequencies $( \pm \mathrm{SD})$} \\
\cline { 2 - 3 } & $\mathrm{SC}$ & $\mathrm{TL}$ \\
\hline Torobarroso & $0.712 \pm 0.027$ & $0.287 \pm 0.027$ \\
Susa & $0.685 \pm 0.026$ & $0.314 \pm 0.026$ \\
Sutatausa & $0.721 \pm 0.019$ & $0.278 \pm 0.025$ \\
Potosi & $0.781 \pm 0.019$ & $0.218 \pm 0.019$ \\
Santillana & $0.676 \pm 0.026$ & $0.323 \pm 0.026$ \\
\hline Total & $0.720 \pm 0.010$ & $0.279 \pm 0.010$ \\
\hline
\end{tabular}

with the SC and TL rearrangement frequencies. Apart from these two, other rearrangements were also present at low, or very low frequencies including the Olympic (OL) and Cuernavaca (CU) rearrangements and a rearrangement similar to the endemic Mexican Amecameca (AM) rearrangement. This is the first time that more than two chromosomal rearrangements (ST \& TL) have been reported in Colombian D. pseudoobscura populations (an analytical work on these new Colombian rearrangements can be found in Ruiz Garcia et al., 2001).

The number of $D$. pseudoobscura larvae encountered during our year-long sampling period was low, and we consider that $D$. pseudoobscura was a very uncommon species during our sampling program. Rearrangement frequency values were very similar in all the populations sampled, with only the Potosi population diverging somewhat. The SC frequency range was between 0.68 and 0.80 .

The results of H-W equilibrium analysis were different from those previously reported, in that no equilibrium was found in any of the populations studied because of homokaryotype excess and heterokaryotype deficit. This was shown by significant values for both Robertson and Hill's (1984) f-statistic, where f-values ranged from 0.94 to 0.99 (Table 4), and Wright's (1965) F-statistics (Table 5) with values between 0.98 and 0.99 , and indicates that the populations

Table 4. F-statistic values (Robertson and Hill, 1984) and variances for five Colombian Drosophila pseudoobscura populations.

\begin{tabular}{lllll} 
Populations & F-value & Variance & $\chi^{2}$ & $\mathrm{H}^{1}$ \\
\hline Torobarroso & 0.9720 & 0.0072 & $131.330^{*}$ & 0.411 \\
Susa & 0.9900 & 0.0067 & 146.035 & 0.403 \\
Sutatausa & 0.9913 & 0.0066 & 148.372 & 0.433 \\
Potosi & 0.9406 & 0.0041 & 215.886 & 0.324 \\
Santillana & 0.9628 & 0.0012 & 157.872 & 0.398 \\
\hline
\end{tabular}

*P $<0.0001$, degrees of freedom $=1,{ }^{1} \mathrm{H}=$ Expected heterozygosity

Table 5. Wright's F endogamy statistic and variance for five Colombian Drosophila pseudoobscura populations.

\begin{tabular}{lccc} 
Populations & F-statistic & Variance & $\chi^{2}$ \\
\hline Torobarroso & 0.9649 & 0.0006 & $129.413^{*}$ \\
Susa & 0.9833 & 0.0003 & 144.065 \\
Sutatausa & 0.9846 & 0.0002 & 146.398 \\
Potosi & 0.9366 & 0.0008 & 214.061 \\
Santillana & 0.9462 & 0.0007 & 152.215 \\
\hline
\end{tabular}

*P<0.0001, degrees of freedom $=1$ 
were very close to homokaryotype fixation. These findings contrast with those of Cárdenas (1988), who found H-W equilibrium in most of the Colombian populations studied by him, as well as the observations of Dobzhansky et al. (1963) and Mayhew et al. (1966), both of whom also found no equilibrium, but in these cases because of heterokaryotype excess.

The results of the analyses presented in Tables 4 and 5 are reinforced by those of Table 6 , which shows the results of a hierarchical Wright's F-analysis $\left(\mathrm{F}_{\mathrm{IT}}, \mathrm{F}_{1 \mathrm{~S}}\right.$, and $\left.\mathrm{F}_{\mathrm{ST}}\right)$. The $\mathrm{F}_{\mathrm{IS}}$ value was 0.961 and the $F_{I T}$ value 0.962 , indicating that there was an important homokaryotype excess both in the subpopulations and at a global level. The significance of the $\mathrm{F}_{\text {IS }}$ value was calculated with 500 jackknife simulations and Table 6 also gives the 95\% (-0.068 to 0.069$)$ and $99 \%(-0.086$ to 0.099$)$ CI with $\mathrm{P}<0.002$ for this value. Because the value of this statistic is clearly outside both $\mathrm{CI}$ the null hypothesis was rejected. The $\mathrm{F}_{\mathrm{IT}}$ value was significant at 0.962 , with $95 \%$ CI of -0.064 to 0.066 and a $99 \%$ CI of -0.082 to $0.078(\mathrm{P}<0.002)$, but the $\mathrm{F}_{\mathrm{ST}}$ value of 0.008 was not significant, falling within the $99 \%$ CI (-0.003 to 0.009). These data show that there was no H-W equilibrium neither in the subpopulation average nor in the total population, whereas the rearrangement frequencies did not significantly differ between the five populations. In other words, the populations were strongly homogeneous.

Table 6. Hierarchical Wright's F-statistics $\left(\mathrm{F}_{\mathrm{IT}}, \mathrm{F}_{\mathrm{ST}}\right.$ and $\left.\mathrm{F}_{\mathrm{IS}}\right)$ for the chromosomal rearrangements of five Colombian Drosophila pseudoobscura populations. The $95 \%$ and $99 \%$ confidence intervals show the limits of the signification of the three Wright's F-statistics.

\begin{tabular}{lrcc} 
& $\mathrm{F}_{\mathrm{IT}}$ & $\mathrm{F}_{\mathrm{ST}}$ & $\mathrm{F}_{\mathrm{IS}}$ \\
\cline { 2 - 4 } 500 Jackknife permutations & 0.962 & 0.009 & 0.961 \\
& 0.010 & 0.013 & 0.010 \\
95\% $\mathrm{F}_{\mathrm{IS}}$ confidence interval & -0.055 & 0.011 & -0.068 \\
& 0.080 & 0.012 & 0.069 \\
$99 \% \mathrm{~F}_{\mathrm{IS}}$ confidence interval & -0.073 & 0.009 & 0.086 \\
& 0.109 & 0.012 & 0.099 \\
$95 \% \mathrm{~F}_{\mathrm{IT}} \& \mathrm{~F}_{\mathrm{ST}}$ confidence interval & -0.064 & -0.003 & -0.071 \\
& 0.066 & 0.005 & 0.068 \\
$99 \% \mathrm{~F}_{\mathrm{IT}} \& \mathrm{~F}_{\mathrm{ST}}$ confidence interval & -0.082 & -0.003 & -0.081 \\
\hline
\end{tabular}

Table 7 shows the factorial correspondence analysis, in which the S1 matrix trace had a value of 0.01608 and the independence test between populations and rearrangement frequencies gave a $\chi^{2}$ value of 13.83 with 8 degrees of freedom (d.f.), these values being nonsignificant. These data again show the great similarity in homo- and heterokaryotype frequencies among the five populations, with all the model's variance being explained by the two first eigenvalues - the first being $0.01363(84.74 \%)$ while the second was $0.00245(100 \%$ as an accumulated percentage). In Table 7, the relative frequencies and the chi-square distances of the populations and the absolute frequencies of the rearrangements are shown, and it can be seen that the population which introduced most variability was the Potosi population, while the Torobarroso population introduced the least variability, while for the variables, the absolute heterokaryotype frequency showed the highest chi-square distance.

Table 8A shows the absolute contribution matrices for populations and chromosome 
Table 7. Factorial correspondence analysis. Trace of S matrix, associated chi-square test, the two highest eigenvalues, variance percentage, relative frequencies and chi-square distances from centroide for rearrangements and populations.

\begin{tabular}{lccc} 
Trace of matrix & $\chi^{2}$ & d.f. & \\
\hline 0.01608 & 13.832 & 8 & \\
& Eigenvalues & Variance percentage & Cumulative percentage \\
1 & 0.01363 & 84.74 & 84.74 \\
2 & 0.00245 & 15.26 & 100.0 \\
Rearrangements & Relative frequencies & Chi-square distance & \\
SC/SC & 0.7127 & 0.0045 & \\
SC/TL & 0.2720 & 0.0353 & \\
TL/TL & 0.0151 & 0.2130 & \\
Populations & & & \\
Torobarroso & 0.1616 & 0.0003 \\
Susa & 0.1814 & 0.0106 \\
Sutatausa & 0.1755 & 0.0117 \\
Potosi & 0.2837 & 0.0328 \\
Santillana & 0.1976 & 0.0137 & \\
\hline
\end{tabular}

$\mathrm{SC}=$ Santa Cruz; TL $=$ Tree Line, d.f. $=$ degrees of freedom

Table 8. A. Absolute contribution matrices for factors (1 and 2) for populations and rearrangements from the factorial correspondence analysis. B. Squared-correlation matrices for factors 1 and 2 for populations and rearrangements from factorial correspondence analysis.

\begin{tabular}{lll|lll}
\multicolumn{2}{l|}{ A. Absolute contribution matrices } & \multicolumn{3}{l}{ B. Squared correlation matrices } \\
\hline Populations & Factor 1 & Factor 2 & Populations & Factor 1 & Factor 2 \\
Torobarroso & 0.0045 & 0.0000 & Torobarroso & 0.9987 & 0.0013 \\
Susa & 0.1109 & 0.1737 & Susa & 0.7800 & 0.2200 \\
Sutatausa & 0.1255 & 0.1432 & Sutatausa & 0.8304 & 0.1696 \\
Potosi & 0.6828 & 0.0030 & Potosi & 0.9992 & 0.0008 \\
Santillana & 0.0762 & 0.6810 & Santillana & 0.3832 & 0.6168 \\
Rearrangements & & & Rearrangements & & \\
SC/SC & 0.2283 & 0.0589 & SC/SC & 0.9556 & 0.0444 \\
SC/TL & 0.6998 & 0.0281 & SC/TL & 0.9928 & 0.0072 \\
TL/TL & 0.0719 & 0.9130 & TL/TL & 0.3043 & 0.6957 \\
\hline
\end{tabular}

$\mathrm{SC}=$ Santa Cruz; $\mathrm{TL}=$ Tree Line

rearrangements, which give the proportion of variance attributable to factors 1 and 2 in each population and rearrangement. It can be seen that the Potosi population accounts for most of the factor 1 variance and the Santillana population for most factor 2 variance. In terms of rearrangements, the TL/TL homokaryotype was the most relevant for factor 1, while the SC/ TL heterokaryotype was most relevant for factor 2 . The squared-correlation matrices for populations and rearrangements are shown in Table $8 \mathrm{~B}$, and give the proportion of variance attributable to factor 1, where variance was caused principally by the Potosi and Torobarroso populations, and factor 2, where the Santillana population was mainly responsible for the population variance. The global relationships between populations and rearrangements are shown in Figure 2.

Table 9 shows both Nei's and Prevosti's genetic distance matrices, and it can be seen 


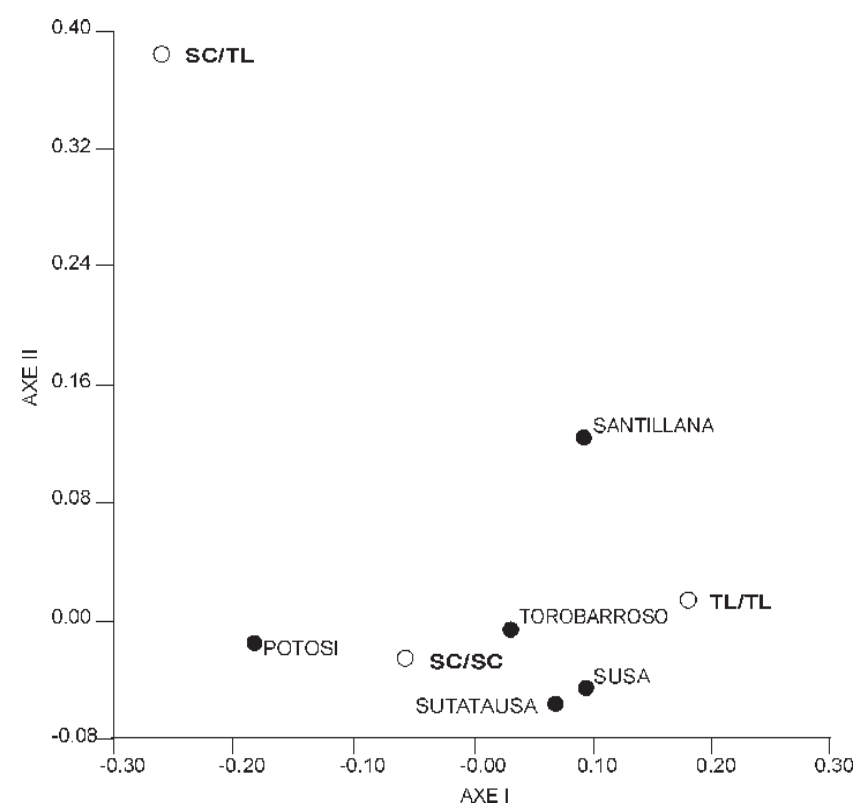

Figure 2. Factorial correspondence analysis using chi-square distance to detect relationships between five Colombian high plateau Drosophila pseudoobscura populations and their respective karyotypes. $\mathrm{SC}=$ Santa Cruz; $\mathrm{TL}=$ Tree Line

Table 9. Genetic distance matrices between five Drosophila pseudoobscura populations from Colombian high plateau using chromosomal rearrangements. Below principal diagonal of the matrix are shown the Nei's genetic distances and in the upper level are the Prevosti's genetic distances.

\begin{tabular}{lccccc} 
Populations & Torobarroso & Susa & Sutatausa & Potosi & Santillana \\
\hline Torobarroso & 0.0000 & 0.0270 & 0.0090 & 0.0850 & 0.0360 \\
Susa & 0.0011 & 0.0000 & 0.0360 & 0.1120 & 0.0090 \\
Sutatausa & 0.0001 & 0.0019 & 0.0000 & 0.0760 & 0.0450 \\
Potosi & 0.0091 & 0.0166 & 0.0072 & 0.0000 & 0.1210 \\
Santillana & 0.0020 & 0.0001 & 0.0030 & 0.0196 & 0.0000
\end{tabular}

that, in general, the genetic distances were small, indicating high genetic homogeneity within this group of Colombian plateau populations. For example, none of Nei's genetic distance pairs were above 0.02 , a limit which is considered an indicator of high genetic similarity and for this reason all the Colombian samples studied can be considered homogeneous for chromosome 3 rearrangements.

The genetic distance dendrograms generated by the UPGMA and WPGMC algorithms were identical (Figure 3), with the Torobarroso and Sutatausa populations forming one cluster

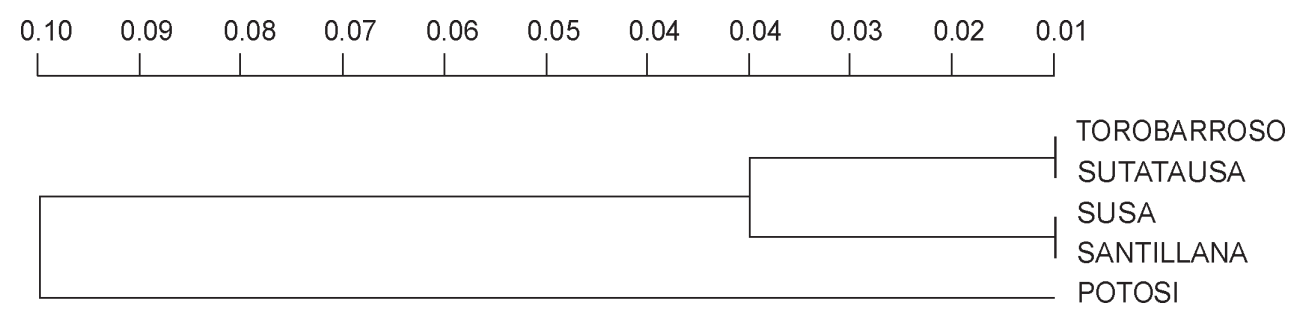

Figure 3. UPGMA phenogram analysis based on Prevosti genetic distance using Santa Cruz and Tree Line rearrangement frequencies from five Colombian high plateau Drosophila pseudoobscura populations.

Genetics and Molecular Research 1 (1): 01-24 (2002) www.funpecrp.com.br 
and the Susa and Santillana populations another, while the Potosi population formed its own cluster. At first sight these trees show no clear correlation between genetic and geographic distance, because such relationships would result in clusters being formed by the Potosi and Santillana populations and the Susa and Sutatausa populations.

The non-parametric Mantel $t$-test (Mantel, 1967) was used to investigate the relationship between genetic and geographic distance. The methods of Nei (1972) and Prevosti (1974) were used to calculate genetic distance, while aerial geographic distance and the great circle method (Sphuler, 1972) were used to measure geographic distance. Correlations were all negative and nonsignificant, for example, the correlation coefficient (r) between Nei's genetic distance and aerial distance was $\mathrm{r}=-0.029$, giving a Mantel $t$-test value of $\mathrm{t}=-0.094(\mathrm{P}=0.4626)$, while a Monte Carlo simulation (MCS) for 2000 random permutations gave $1145<\mathrm{Z}, 14=\mathrm{Z}$ and 841 $>\mathrm{Z}$ (one-tailed, $\mathrm{P}=0.4280$ ). The correlation coefficient between Prevosti's genetic distance and great circle geographic distance was $r=-0.197$, giving $t=-0.479(P=0.3159)$ and MCS for 2000 random permutations of $829<\mathrm{Z}, 23=\mathrm{Z}$ and $1148>\mathrm{Z}$ (one-tailed, $\mathrm{P}=0.4265$ ). Prevosti's genetic distance gave more negative correlation coefficients than Nei's genetic distance, while the greatcircle geographic distance gave the same results as aerial geographic distance.

Table 10 compares the frequency of SC rearrangements in the Torobarroso, Potosi and Santillana populations as studied by Cárdenas in 1982 and 1986 (Cárdenas, 1988) and by us in the present study, carried out in 1997. During the approximately 10-year period (about 180

Table 10. Changes in the frequency of the Santa Cruz (SC) rearrangement between 1982-1986 and 1997 in three Colombian high plateau Drosophila pseudoobscura populations.

\begin{tabular}{lccrl} 
& \multicolumn{2}{c}{ Frequency of SC rearrangement } & \multirow{2}{*}{$\chi^{2}$} & Probability \\
\cline { 2 - 3 } & $1982-86^{*}$ & $1997^{\#}$ & & \\
\hline Torobarroso & 0.71 & 0.66 & 3.39 & nonsignificant \\
Potosi & 0.78 & 0.63 & 57.28 & $\mathrm{P}<0.001$ \\
Santillana & 0.67 & 0.58 & 5.82 & $\mathrm{P}<0.01$ \\
\hline
\end{tabular}

degrees of freedom $=1,{ }^{*}$ Cárdenas, $1988,{ }^{\#}$ Present work

generations) between these two studies there was no significant difference in the SC frequency for the Torobarroso population, but there was a statistically significant increase in SC frequency from 0.63 to 0.78 for the Potosi population $\left(\chi^{2} \approx 57.3, \mathrm{P}<0.001\right)$ and from 0.58 to 0.67 for the Santillana population $\left(\chi^{2} \approx 5.8, \mathrm{P}<0.01\right)$.

The average value for the SC rearrangement frequency as found by Dobzhansky et al. (1963) was 65.6\%, by Mayhew et al. (1966) 62.7\%, by Cárdenas (1988) $64.2 \%$ and by us in the present study (carried out in 1997) $72.0 \%$, suggesting a progressive increase in the SC frequency accompanied by a corresponding decrease in the TL frequency in all the Colombian plateau populations during the last decade. In our study the SC frequencies were between about 0.60 and 0.80 , with no conspicuous oscillations occurring between the monthly collections. In no case were the TL frequencies superior to the SC frequencies in any population.

\section{DISCUSSION}

The majority of rearrangements identified in the present study were the Santa Cruz (SC) and Tree Line (TL) rearrangements, which is in agreement with previous reports. However, 
the Olympic (OL) and Cuernavaca (CU) rearrangements as well as one similar to the Mexican Amecameca (AM) rearrangement, none of which have been reported before in Drosophila pseudoobscura bogotana, were observed by us at a very low frequency. This leaves in doubt the statement by Polanco et al. (1987), who said that only two rearrangements are present in Colombia. The discovery of new rearrangements shows not only the system's complexity but also its antiquity, showing the importance of groups of physically linked genes.

In the Colombian populations that we studied, there was a higher SC frequency $(0.60$ to 0.80 ) compared to the TL frequency ( 0.20 to 0.40$)$, which is the opposite to that observed in North American populations, where the Standard (ST), Arrowhead (AR) and Chiricauha (CH) rearrangements are the most frequent (Dobzhansky, 1971). Moreover, in Californian samples, where SC and TL rearrangements have sometimes been found, the TL rearrangement, at a frequency of about $10 \%$, is always more frequent than the SC rearrangement, which occurs at about 1\% (Dobzhansky, 1963). This could mean that on the Colombian plateau, at least over the last 35 years (and probably thousands of D. pseudoobscura generations), there are ecological and selective pressures different from those present in North America as reported by Dobzhansky, Anderson and others.

In most of the Mexican populations the CU rearrangement was the most common, except for the Ciudad Guzman (Colima) population where the SC rearrangement was predominant at a frequency of 0.657 , similar to that found in the Colombian populations. Ciudad Guzman is a population located in the Western Sierra Madre, at a similar altitude and with similar environmental conditions to the Colombian plateau (Guzman et al., 1993). It is noteworthy that the Central Mexican Valley zone had more than 23 reported rearrangements (Olvera et al., 1979, 1985), while in Colombia, with similar climatic conditions, only two rearrangements are present at significant different frequencies. An ancestral founder effect and changing relationships in the adaptability of each rearrangement in regard to those present in a particular population could be important points for explaining differences in the number of chromosomal rearrangements in populations at similar altitudes in neotropical countries with comparable climates.

Pavlovsky and Dobzhansky (1966) provide a clear example of what can happen under laboratory conditions, where the coexistence of the PP and ST rearrangements produced an heterotic heterokaryotype while the coexistence of PP and AR produced a heterokaryotype with lower adaptability than the homokaryotypes. Nevertheless, there seem to be no rules for predicting genetic profiles in a given population from season, climate or altitude (Levine et al., 1995 ) and each population could have a unique partial genetic structure.

The genetic characteristics of $D$. pseudoobscura chromosome 3 reported in the studies of Dobzhansky in USA and Mexico seem to conform to the model predicted by Carson (1959, 1965), high polymorphism, developmental homeostasis (Alvarez et al., 1989; Alvarez, 1993; Ruiz-Garcia and Alvarez, 1997a) and detectable heteroselection in the central range populations. This point of view is supported by many laboratory experiments with central range flies, the first being those made by Wright and Dobzhansky (1946) using a Californian population from Pinon Flats in which the fitness coefficient of the rearrangement heterokaryotype was maximal $(\mathrm{ST} / \mathrm{CH}=1)$ and homokaryotypes were at a selective disadvantage $(\mathrm{ST} / \mathrm{ST}=0.7$ and $\mathrm{CH} / \mathrm{CH}$ $=0.3$ ). Another example are the long-term equilibrated polymorphisms cited by Levine and Beardmore (1959), Dobzhansky (1960) and Strickberger (1963) containing the AR and CH rearrangements at an initial frequency of 0.2 and 0.8 , respectively, which after 60 to 120 plus generations reached an equilibrium in which $\mathrm{AR}=0.8$ and $\mathrm{CH}=0.2$, only altered by infections that changed the intensity and direction of the selective pressures (Druger, 1962).

Heterosis has also been detected in flies with the AR and $\mathrm{CH}$ arrangements grown in the laboratory at $25^{\circ} \mathrm{C}$ (Dobzhansky, 1948; Levene et al., 1954), but this heterosis was lost 
when the flies were grown at $16^{\circ} \mathrm{C}$. On the tropical Colombian plateau the average temperature is about $14^{\circ} \mathrm{C}$, but oscillates between $8^{\circ} \mathrm{C}$ and $16^{\circ} \mathrm{C}$ for a significant portion of the day, a temperature range significantly lower than that found in North America. During the night, the temperatures on the plateau fluctuate between $0^{\circ} \mathrm{C}$ and $6^{\circ} \mathrm{C}$, but on some occasions can fall to $-6^{\circ} \mathrm{C}$. It may be that some heterotic effects related to high temperatures and linked to chromosome 3 rearrangements in central range $D$. pseudoobscura populations could be missing in Colombian plateau populations, although this does not explain the high homokaryotype excess detected by us in the Colombian populations and not reported in previous studies.

Nevertheless, it is a fact that Dobzhansky's studies on Colombian marginal populations did not conform to Carson's model $(1959,1965)$, because although homoselection should have occurred in these populations, heterokaryotypes or $\mathrm{H}-\mathrm{W}$ equilibria were found which are more characteristic of central-range populations. On the other hand, the data reported in the present paper suggest strong and constant homoselection with loss of genetic variability, a picture which is in agreement with Carson's theory, so how can this apparent paradox be explained? The answer could be the following.

Dobzhansky et al. (1963), Mayhew et al. (1966) and Cárdenas (1988) showed that this species was abundant in the Colombian plateau when they made their respective studies. In the first study, it was stated that "we are faced with an isolated population inside the central region of the eastern Colombian Andes, but inside this island, the species is very common", that is to say that at that time D. pseudoobscura was marginal geographically but not ecologically. This may have been due to good adaptation by this fly to the tropical Colombian habitat, with these habitats not being ecologically marginal to the fly genotypes, in disagreement with Carson's model. However, due to human intereference during the last 10 years there has been significant alteration in the habitats of all the studied populations. One of us (D.A.) sampled in some of these localities in the 1980's, but when she resampled 1996 and 1997 she found the sites very much changed because of deforestation and the presence and expansion of cattle ranches. These changes, plus the climatic changes which occurred in 1996 and 1997 in the neotropics due to the Pacific El Niño phenomenon (O. Vargas, personal communication), could explain why the populations described in this paper were (unlike the situation in other decades) in an ecologically marginal situation in 1990's and submitted to homoselection pressure as was proposed by Carson for isolated environments. If the deforestation and habitat degradation hypothesis is true, we would expect a constant homoselection process during the next few years because the habitats will tend to be more altered by human action. On the other hand, if climatic factors such as El Niño are more important we should be able to detect cyclic changes due to heterokaryotypic excess and defects in the next few years. Future sampling programs could help to clarify the situation with regard to the above hypothesis.

Some answers to the questions posed in the introduction follow:

Firstly, in contrast to North American populations from California (Dobzhansky and Queal, 1938), Texas (Dobzhansky, 1939) and Mexican populations from Amecameca (Levine et al., 1995), the micro-geographic heterogeneity for chromosome 3 rearrangements of the Colombian plateau populations was very low. This was previously detected by Dobzhansky et al. (1963), but was opposite to that found by Cárdenas (1988). This could mean that in North America and Mexico there were ecological features that changed drastically in time and space, while conditions were constant in the Colombian plateau populations studied by us during 1996 and 1997.

Secondly, another interesting difference between central range and Colombian populations was that in the latter rearrangement frequencies were usually constant during the whole year. In the current study, as in that by Cárdenas (1988), the SC rearrangement frequency was 
higher than the TL frequency, with only a few cases in which the TL frequency was approximately equal to the SC frequency, but even then the oscillations were not substantial. In North American populations, however, important seasonal and yearly changes in the frequency of some rearrangements have been reported. Dobzhansky (1943), has reported that in MayJune when the temperature was high the Piñon Flats population contained the lowest ST and highest AR rearrangement frequencies, but the situation was reversed in September-November when the temperature decreased, with a high ST and low AR frequency. Strickberger and Wills (1966) reported the inverse situation in a population near Berkeley, in which ST frequency reached a maximum in summer and minimum in winter while AR frequency did not change seasonally, with the $\mathrm{CH}$ frequency being low in summer and high in winter. Similar phenomena involving other rearrangements have been reported in the Mexican Amecameca population, in which the CU rearrangement frequency decreased between May and August while the TL frequency increased and the Estes Park (EP) rearrangement frequency increased slightly (Levine et al., 1995). In the Colombian plateau there are no temperature-related seasons, but there could exist uniform selective pressure involving many ecological conditions acting consistently throughout the whole year. This could explain why rearrangement frequencies did not change during the course of our study.

We have already commented that the populations studied showed an important homokaryotype excess and we propose that these populations are affected by stabilizing selection favoring homokaryotypes. In general, for most of the year the homokaryotype with highest adaptability (fitness score, W) would be the SC/SC homokaryotype, with the TL/TL homokaryotype generally having a lower fitness score and the SC/TL heterokaryotype the lowest. With some non-temperature-related microclimatic changes (such as precipitation levels, etc.), the TL/TL fitness score could sometimes increase to near unity, allowing the coexistence of both arrangements and an excess of homozygotes with the SC/SC rearrangement having the highest frequency.

It could be argued that such a homokaryotype excess could be caused by some kind of stochastic process such as genetic drift or a founder effect, that are usually associated with consanguinity (inbreeding). If the subpopulations have a low effective number (Crawford, 1984), endogamy should be favored because of the limited availability of sexual partners. However, the presence of inbreeding and/or genetic drift in these populations can easily be discarded, because if genetic drift was present there would not be such a low $\mathrm{F}_{\mathrm{ST}}$ value $(0.008)$ and there would be statistically significant differences between subpopulations. The genetic homogeneity, detected by genetic distance analysis, shows that a process such as stabilizing selection is more probable than genetic drift, although this does not mean that the effective numbers of these populations are high.

Currently, our group is studying the same populations using molecular markers including nuclear DNA STRPs and mtDNA RFLPs. If the differences between populations as measured by $\mathrm{F}_{\mathrm{ST}}$ values were higher using these markers it should be possible to probe for stabilizing selection regarding chromosome 3 rearrangements. In our studies on the Colombian $D$. pseudoobscura populations, using five microsatellite loci (DPSX001, DPS2001, DPS3001, DPS3002 and DPS4001), an $\mathrm{F}_{\mathrm{ST}}$ value of 0.042 was obtained (Alvarez et al., 2000), five times greater than the $\mathrm{F}_{\mathrm{ST}}$ value of 0.008 obtained using chromosome 3 rearrangements, with most of these microsatellite loci being in $\mathrm{H}-\mathrm{W}$ equilibrium. Furthermore, for one microsatellite locus (DPS4001) the $\mathrm{F}_{\mathrm{ST}}$ value between the Colombian populations was 0.081 , which is 10 times greater than the value based on chromosome 3 rearrangements. These data indirectly support the presence of some stabilizing selective agent currently acting on the Colombian populations for the chromosome 3 rearrangements. 
Crumpacker et al. (1974) showed that a bottleneck occurred in the Rist Canyon population in 1967, with a decrease in the normally high frequency of the AR rearrangement and an increase in locally rare rearrangements such as TL, EP and ST. The frequency change of these arrangements is very difficult to explain by genetic drift, but could be explained by the presence of a strong selective pressure during a period of environmental stress that caused a reduction in the population - a mechanism that could also have operated in our populations. It can also be argued that homogeneity could have been produced by elevated gene flow (Nm) between populations, but if this had happened we would expect the greatest similarity to occur between geographically adjacent populations, which was not the case. Also, if gene flow were high and there was a unique gene pool in all the populations we should detect $\mathrm{H}-\mathrm{W}$ equilibrium, but this was not found. If there were high gene flow between diverse and different gene pools present in each population, or if there was sex-differential gene flow (a negative Wahlund effect, q.v. Ruiz-Garcia and Alvarez, 1997b), a heterozygote excess would be expected, which also did not occur.

Crumpacker and Williams (1973) have noted that D. pseudoobscura dispersion rates in the central distribution range are high, with values of almost $170 \mathrm{~m}$ one day after release. Powell et al. (1976) have concluded that the dispersion rate is so high that it could homogenize populations occurring within one kilometer, but the Columbian populations we studied are separated by more than that distance. It thus seems that gene flow is a less plausible mechanism than stabilizing selection.

Inbreeding is also not a good explanation, because the F-range fluctuation is 0.94 to 0.98), and it is unlikely that all the populations would independently reach such similar inbreeding coefficients. A positive F-range is to be expected, but the range should be broader because the original structure of these populations, their history, and effective numbers have unique characteristics and are very difficult to generalize. The restricted F-range value is a typical result of stabilizing selective pressures (Lewontin and Krakauer, 1973).

It seems that the Colombian populations are not flexible systems, like those found in North America and Mexico, nor are there abrupt separation zones at a micro-geographic level between populations with flexible and rigid systems, like those found in Colorado by Crumpacker and Williams (1974). These authors detected two kinds of systems in Colorado, one population in northern Denver that colonized a site with luxurious macro- and microflora had a rigid system of chromosomal polymorphisms, while another population in southern Denver at a site with poor macro- and microflora had a flexible system. They suggested that this would also occur in St. Jacinto, where there is a population with a rigid polymorphism scheme that colonizes a mature forest. In Colombia, the situation is not quite the same because there are populations with a rigid system of chromosomal polymorphisms existing in marginal ecological situations. Some North American D. pseudoobscura populations with rigid polymorphism schemes under marginal conditions have been discovered in Jacksonville in the Yosemite region.

Thirdly, it seems that there is no simple answer to the question as to which selective agents are producing this stabilizing pressure in favor of homokaryotypes. In more than 50 years of research, scientist have not yet clarified which selective factors are present in the North American populations even though they have analyzed many potential causes.

The small number of flies collected by us, because the species is not as abundant now as it was in past years when other workers carried out their studies, makes us think that the $D$. pseudoobscura populations are suffering stress that affect population size. Our results seem to be in disagreement with the hypothesis of Parsons (1971), which predicts that in marginal environments heterokaryotypes have an advantage over homokaryotypes. The phenomenon of heterokaryotype advantage has been reported many times, for example by Heuts (1948) for 
cold tolerance and by Parsons and McKenzie (1971) for desiccation tolerance. It would be contradictory to suppose that in the early 1960's when Dobzhansky et al. (1963) made their study the species was in an environmentally extreme situation that produced selection favoring heterokaryotypes while at the same time being very abundant inside the Colombian plateau, since today the species is in an optimum environment (without heterosis) but less abundant at all the sites sampled. These considerations seem to favor the hypothesis of Carson as opposed to that of Parsons.

Working with North American Berkeley populations, Strickberger and Wills (1966) stated that the $\mathrm{CH}$ rearrangement was favored by high rain levels and the ST rearrangement by an arid environment. Dobzhansky (1971) also showed the presence of increases and decreases in the frequency of ST and AT rearrangements during many years in populations from Mather, California, and related these changes to a succession of wet and dry years, although in many years there was no significant correlation. Such a selection mechanism could operate in Colombia if the El Niño phenomenon had affected the climatic conditions. Unlike temperature regions, in the Colombian plateau there are seasonal changes in precipitation, but we found no associated oscillations in rearrangement frequencies.

Battaglia and Smith (1962) showed that D. pseudoobscura populations that were more polymorphic and which had more chromosomal rearrangements produced both more flies and heavier flies, while less polymorphic populations at the same density produced less biomass than populations with more rearrangements. The presence of only two principal chromosomal rearrangements in Colombian populations make the adaptive value of these two rearrangements different from that of rearrangements found in populations with more arrangements (Levene et al., 1954, 1958; Pavlovsky and Dobzhansky, 1966). If we accept that today the Colombian plateau populations are geographically and ecologically marginal, then the fact that they have a low number of rearrangements would be advantageous for subsisting in habitats with scarce trophic resources and carrying capacity. Although this explanation is very adequate for our data it would not explain the situation reported either by Dobzhansky et al. (1963) or Cárdenas (1988).

The above answers to the questions posed in the introduction are not the only factors that should be considered in trying to explain the chromosomal constitution of Colombian plateau populations.

Birch (1955) found that when eggs, larvae and pupae were in high densities the ST rearrangement was more frequent than the $\mathrm{CH}$ rearrangement, while in low-density populations the $\mathrm{CH}$ rearrangement was more common. Such a mechanism could explain the situation observed in Piñon Flats and St. Jacinto, in which in early spring (when the hibernation period had just finished) $\mathrm{CH}$ was the most frequent rearrangement while ST was present at a low frequency. As trophic resources grew during the spring the D. pseudoobscura population density also increased and reached a maximum during early summer, when the ST rearrangement also reached its highest frequency and the $\mathrm{CH}$ its lowest. During summer the conditions became unfavorable for this species, and the $\mathrm{CH}$ frequency decreased further while the $\mathrm{ST}$ rearrangement became abundant.

This explanation, however, is not satisfactory for other parts of North America, since it has been shown that in some Californian populations such as those in Mather or Berkeley (Strickberger and Wills, 1966) the highest ST frequency was reached in August to September, although it is possible that because of the particular ecological conditions prevailing in these areas $D$. pseudoobscura had more elevated population densities during these months. Crumpacker and Williams (1974) found that the AR rearrangement also had higher fitness scores in early spring when the population density was low, but when competition became stronger because of increased population density the AR frequency diminished in favor of 
other rearrangements. Such a model is more related to population density and the availability of resources than to seasonal climatic changes. The fact that the $D$. pseudoobscura population density is now low on the Colombian plateau and that climatic changes are moderated could avoid drastic variations in population density. The slight, but significant, growth in SC frequency that has recently occurred in some Colombian populations as compared to previously reported $\mathrm{SC}$ frequencies, could be caused by low population density diminishing competition, favoring the SC rearrangement. Thus, the SC rearrangement might be playing a similar role to that of the $\mathrm{CH}$ rearrangement in California, while the TL rearrangement might be playing the role of the Californian ST or AR rearrangement. The slight increase in TL frequency that we detected during some months could be due to low population density growth caused by slight variations in non-temperature-related factors. It should be remembered, however, that none of these changes had the dimensions of those observed in North America.

In the central range populations, the size and density oscillations of the populations have been associated with changes in climate and the availability of resources, but they are also related to the population density of potential competitor species such $D$. persimilis, $D$. miranda and D. azteca (Dobzhansky, 1963). In our samples, the number of Drosophila species was constant during the whole year at usually 5-6 species, so it appears that changes in rearrangement frequency associated with the abundance of competitors either does not happen in Colombian populations, or such changes are small.

Prakash and Lewontin (1968) showed that there are observable enzymatic and protein variant differences in Drosophila with different chromosomal rearrangements which could be important in linking chromosomal rearrangements and environmental, trophic or competitive selective pressures. The allelic frequencies of many isoenzyme loci are very different for the central range and the Colombian plateau populations (Prakash et al., 1969; Ayala and Dobzhansky, 1974; Singh et al., 1976; Coyne and Felton, 1977), and differences can also be seen between nucleotide sequences for the ADH and ADH Dup loci (Schaeffer and Miller, 1991, 1992) and between some microsatellite loci. For instance, we have detected some alleles in the Colombian populations which are not present in the North American populations, e.g., a 203-bp allele at the DPSX001 locus, three 193-bp, 200-bp and 201-bp alleles at the DPS2001 locus, two 277-bp and 273-bp alleles at the DPS3002 locus and two 276-bp and 277-bp alleles at the DPS4001 locus. Mayhew et al. (1966) have shown that each rearrangement carries a different lethal spectrum.

Another feature that is different between Colombian and North American populations, is the presence of triads (three rearrangements in linear sequence in a rearranged phylogenetic tree; Wallace, 1953, 1954, 1959). When a triad occurs in a population, gene transference can break co-adapted gene complexes that can be present in inversions. In some populations (e.g., North American populations) selective environmental factors change locally and temporally, and it is possible to find triads in the population because the serial transfer of genes from one inversion to another can change direction, although triad rearrangement will always be limited and can fluctuate with time, an example being the Austin population containing AR-ST-PP described by Anderson et al. (1967). The absence of triads in the Colombian plateau populations may be explained by co-adapted gene complex breakage inside the inversions. In this case a founder effect and/or bottleneck would be fundamental in producing a low frequency of chromosomal rearrangement in the Colombian populations, but not so radical as to leave only the SC and TL rearrangements, although a phenomenon such as this could in theory make a rearrangement such as ST practically disappear.

The changes in Colombian plateau populations involving increasing SC frequency, decreasing TL frequency and a change from heterokaryotype fitness in the 1960's to homo- 
karyotype fitness in the late 1990's, could also be explained if although the SC and TL rearrangements were cytologically equal to those analyzed by Dobzhansky et al. (1963) or Cárdenas (1988) but there was a genetic reconstruction inside each rearrangement in a way that can be only detected at the molecular level. Pavlovsky and Dobzhansky (1966) found that some of the rearrangements in the Mather population, although cytologically identical, showed a different behavior in samples collected in 1959 compared with samples taken in 1945 and 1946 (Dobzhansky, 1948). These authors suggested that such differences could be produced by genetic reorganization inside some rearrangements in the Mather population, and it is possible that a similar mechanism could currently operate in the Colombian plateau populations studied by us.

It is possible for selective phenomena such as climatic, trophic or competitive change to affect genetic composition in two different ways, one being that selection could occur which would modify the fitness of each genotype in the population, while another way is that new genetic variants could arise by mutation or recombination inside existing rearrangements (supergenes). Dobzhansky (1971) has suggested that super-genes, better co-adapted to some habitats, could arise in a population, and, hypothetically, this is what could have occurred during the last 10-12 years in the Colombian plateau populations. The frequency of the SC/SC and TL/TL homokaryotypes could have increased because of better fitness, contrary to what was observed in the 1960's by Dobzhansky et al. when the heterokaryotype had the best fitness. New SC variants may have arisen that substituted the old SC rearrangements because the new variants had better co-adapted super-genes that worked best in homozygotes. This type of effect is more likely to occur in populations subjected to conditions such as those occurring in the Colombian plateau than in North American populations (which have rare rearrangements such as PP or TL) because the new combinations into these rearrangements occurring under Colombian conditions can be separated in homokaryotypes by recombination. In North American populations, the rare rearrangements therefore would be found in heterokaryotypes and crossing over would be suppressed in heterozygote inversions, with the result that the formation and disruption of new gene complexes would be a very improbable phenomenon. On the contrary, the appearance of new complexes in a major rearrangement such as the SC rearrangement, which is mostly found homokaryotypically, is more likely in Colombian plateau populations. In their adaptive complex hypothesis, Anderson et al. (1975) remarked that the appearance and retention of new complexes in a population until their frequencies are high enough to not be eliminated by stochastic processes also require diffusion.

In unfavorable habitats, this species could extend more than $10 \mathrm{~km}$ from the point of release (Coyne et al., 1982, 1987), but such dispersion is not enough to homogenize all the Colombian plateau populations studied since the total linear distance covered by the population is more than $150 \mathrm{~km}$. Strong passive dispersion associated with human activities would be needed to spread new complexes by gene flow, but it is doubtful if this happened in Colombia because the effective numbers of these Drosophila populations are lower than in North America, and in Colombia this Drosophila species seems not to be associated with any fruit actively transported by humans. Also, if a new complex reached all the populations by gene flow they could have similar SC and TL frequencies but not necessarily the same F value (homokaryotype excess), while if stabilizing selection favoring homokaryotypes were not present and gene flow were high we would expect $\mathrm{H}-\mathrm{W}$ equilibrium. In addition, no explanation can be given as to why the Potosi population was different from the neighboring Santillana population and the rest of populations sampled with regard to chromosomal rearrangements and morphologic and allozymic distances (Ruiz-Garcia and Alvarez, 1997a), unless the Potosi population was affected by genetic drift or another selective process different from the one found in the other Colombian 
plateau populations. Moreover, the new genetic complex (super-gene) should be advantageous in all the habitats in Colombia where D. pseudoobscura is present, although these habitats were very different. Anderson et al. $(1967,1975)$ made the same proposition for the PP and TL rearrangements that seemed to increase their frequencies in the western USA, but in laboratoryreared populations there was no evidence that these rearrangements increased their frequencies, as would be expected if they were carrying a new adaptive complex that allow them to be favorably selected in any environment. Anderson et al. (1975) remarked that one alternative could be that the rearrangement quickly modified its structures and adaptive complexes (or super-genes) during the dispersion process, and that the same rearrangement carried different characteristics in different places. This scenario seems unlikely to have occurred in the Colombian plateau populations, because in this case it would be difficult to independently produce different SC rearrangements that always favored the homokaryotype at practically the same frequency. One has to admit that an adaptive complex of the type described should belong to a rigid, non-flexible, polymorphism category, which seems to be the case with chromosome 3 rearrangements in Colombian plateau populations. However, at the moment we prefer to think that the selective events that are taking place in Colombia are due to environmental changes, especially trophic changes, or changes associated with human action or climatic events such as El Niño, and not to the emergence of new and better co-adapted complexes or super-genes.

As Carson et al. (1956) and Phaff et al. (1956) suggested, the presence or absence of appropriate trophic factors such as yeasts and bacteria can be a more important selective agent than those associated with climatic changes. One of the few studies made to determine the importance of trophic factors was carried out by Brito da Cunha (1951), who demonstrated in the laboratory that the relative adaptation values of ST and $\mathrm{CH}$ homo- and heterokaryotypes were variable depending on the kind of yeast and bacteria supplied to the flies as food. Samples with a large variety of these microorganisms favored heterokaryotypes, but at least two yeast species favored the ST/ST homokaryotype. Yeasts differ in the amount of vitamins and other nutrients that can be useful to the flies, and we believe that this is a basic factor in explaining many of the chromosomal differences found between central range and Colombian plateau populations. Climatic and ecological fluctuations and variations may change microbial population dynamics, affecting a differential response in terms of Drosophila chromosomal rearrangements. At present we are analyzing the microflora of the sites where our Drosophila samples were collected, and it seems that the microfloral composition seems to be constant during the whole year and different to that found in North America. More detailed studies are underway which will provide more data on this interesting area.

The morphological, chromosomal and molecular studies, some of which involve nuclear DNA STRPs and mtDNA RFLP analysis, that are currently being carried out by us on Colombian plateau $D$. pseudoobscura populations will profile more precisely some of the evolutionary factors that are playing a role in the genetic structure of this insect.

\section{ACKNOWLEDGMENTS}

The authors, especially D. Alvarez and M. Ruiz-Garcia, thank Dr. Victor Salceda and his wife, from the Instituto de Investigaciones Nucleares, Mexico, for help in the determination of rare rearrangements and for their hospitality. Thanks are also due to the people that facilitated the sampling on the tropical Colombian plateau. Reseach partially supported by Colciencias grants 139-94 \& 140-96 (Decree 1742, 1994) to M. Ruiz-Garcia and grant CT-390 (Programa Estimulo a los Investigadores) to D. Alvarez. 


\section{REFERENCES}

Alvarez, D. (1993). Variación de caracteres cuantitativos en poblaciones naturales de Drosophila pseudoobscura del altiplano cundiboyacense (Colombia). MSc. thesis, Universidad de Los Andes, Bogotá, Colombia.

Alvarez, D., Iannini, A., Cárdenas, H. and Hoenigsberg, H. (1989). Population genetics in the American Tropics. Asymetry as a divergence factor in demes of Drosophila pseudoobscura un the Cundiboyacense altiplano of Colombia. Evol. Biol. 3: 269-311.

Alvarez, D., Noor, M. and Ruiz-García, M. (2001). Comparative genetic structure among Colombian and North American Drosophila pseudoobscura populations using the microsatellite loci DPSX001, DPS2001, DPS3001, DPS3002 and DPS4001. Biotropica 38: (in press).

Anderson, W.W., Dobzhansky, Th. and Pavlovsky, O. (1967). Selection and inversion polymorphism in experimental populations of Drosophila pseudoobscura initiated with the chromosomal constitutions of natural populations. Evolution 21: 664-671.

Anderson, W.W., Oshima, C., Watanabe, T., Dobzhansky, Th. and Pavlovsky, O. (1968). Genetics of natural populations. XXXIX. A test of the possible influence of two insecticides on the chromosomal polymorphism in Drosophila pseudoobscura. Genetics 58: 423-434.

Anderson, W.W., Dobzhansky, Th., Pavlovsky, O., Powell, J. and Yardley, D. (1975). Genetics of natural populations XLII. Three decades of genetic change in Drosophila pseudoobscura. Evolution 29: 24-36.

Anderson, W.W., Arnold, J., Baldwin, D.G., Beckenbach, A.T., Brown, C.J., Bryant, S.H., Coyne, J.A., Harshman, L.G., Heed, W.B., Jefferey, D.E., Klaczko, L.B., Moore, B.C., Porter, J.M., Powell, J.R., Prout, T., Schaeffer, S.W., Stephens, J.C., Taylor, C.E., Turner, M.E., Williams, G.O. and Moore, J.A. (1991). Four decades of inversion polymorphism in Drosophila pseudoobscura. Proc. Natl. Acad. Sci. USA 88: 10367-10371.

Aquadro, C.F., Weaver, A.L., Schaeffer, S.W. and Anderson, W.W. (1991). Molecular evolution of inversions of Drosophila pseudoobscura: the amylase gene region. Proc. Natl. Acad. Sci. USA 88: 305-309.

Ashburner, M. (1969). Drosophila. A Laboratory Handbook. Cold Spring Harbor Laboratory Press, New York, NY, USA.

Ayala, F.J. and Dobzhansky, Th. (1974). A new subspecies of Drosophila pseudoobscura. Pan-Pac. Entomol. 50: 211-219.

Battaglia, B. and Smith, H. (1962). The Darwinian fitness of polymorphic and monomorphic populations of Drosophila pseudoobscura at 16 C. Heredity 13: 475-484.

Birch, C.L. (1955). Selection in Drosophila pseudoobscura in relation to crowding. Evolution 9: 389-399.

Bernal, G. (1989). Cundinamarca: Características Geográficas. IGAC, Bogotá, Colombia.

Brito da Cunha, A. (1951). Modification of the adaptive values of chromosomal types in Drosophila pseudoobscura by nutritional variables. Evolution 5: 395-404.

Cárdenas, H. (1988). Equilibrio Robertsoniano en los más antiguos arreglos cromosómicos Santa Cruz y Tree Line de Drosophila pseudoobscura con estructura démico-ancestral. MSc. Thesis, Univerdidad de Los Andes, Bogotá, Colombia.

Carson, H.L. (1955). The genetic characteristics of marginal populations of Drosophila. Cold Spring Harbor Symp. Quant. Biol. 20: 276-287.

Carson, H.L. (1956). Marginal homozygosity for gene arrangement in Drosophila robusta. Science 123: 630-631.

Carson, H.L. (1959). Genetic conditions which promote or retard the formation of species. Cold Spring Harbor Symp. Quant. Biol. 24: 87-103.

Carson, H.L. (1965). Chromosomal morphism in geographically widespread species of Drosophila. In: The Genetics of Colonizing Species (Baker, H.G. and Stebbins, G.L., eds.). Academic Press, New York, NY, USA, pp. 508-531.

Carson, H.L., Knapp, E.P. and Phaff, H.J. (1956). Studies on the ecology of Drosophila in the Yosemite region of California. III. The yeast flora of the natural breeding sites of some species of Drosophila. Ecology 37: 538-544.

Coyne, J.A. and Felton, A.A. (1977). Genic heterogeneity at alcohol dehydrogenase loci in Drosophila pseudoobscura and Drosophila persimilis. Genetics 87: 285-304.

Coyne, J.A., Boussy, I.A., Prout, T., Bryant, S.H., Jones, J.S. and Moore, J.A. (1982). Log-distance migration of Drosophila. Am. Nat. 119: 589-595.

Coyne, J.A., Bryant, S.H. and Turelli, M. (1987). Long-distance migration of Drosophila. 2. Presence in desolate sites and dispersal near a desert oasis. Am. Nat. 129: 847-861.

Crawford, M.H. (1984). What is a population. In: Evolutionnary Ecology. The 23rd Symposium of the British Ecological Society (Shomocks, B.S., ed.). Blackwell Scientific Publication, Oxford, England, pp. 135-173.

Crumpacker, D.W. and Williams, J.S. (1973). Density, dispersion, and population structure in Drosophila pseudoobscura. Ecol. Monogr. 43: 499-538.

Crumpacker, D.W. and Williams, J.S. (1974). Rigid and flexible chromosomal polymorphisms in neighboring populations of Drosophila pseudoobscura. Evolution 28: 57-66.

Crumpacker, D.W., Pyati, J. and Ehrman, L. (1974). Ecological genetics and chromosomal polymorphism in Colorado populations of Drosophila pseudoobscura. In: Genetic Lectures (Bogart, R., ed.). Vol. 5. Oregon State University Press, Corvallis, OR, USA.

Dobzhansky, Th. (1937). Genetics and the Origin of Species. Columbia University Press, New York, NY, USA.

Dobzhansky, Th. (1939). Microgeographic variation in Drosophila pseudoobscura. Proc. Natl. Acad. Sci. USA 25: 311-314.

Dobzhansky, Th. (1943). Genetics of natural populations. IX. Temporal changes in the composition of populations of Drosophila pseudoobscura. Genetics 28: 162-186.

Genetics and Molecular Research 1 (1): 01-24 (2002) www.funpecrp.com.br 
Dobzhansky, Th. (1947a). Adaptive changes induced by natural selection in wild populations of Drosophila. Evolution 1: 1-16. Dobzhansky, Th. (1947b). A directional change in the genetic constitution of a natural population of Drosophila pseudoobscura. Heredity 1: 53-64.

Dobzhansky, Th. (1948). Genetics of natural populations. XVI. Altitudinal and seasonal changes produced bynatural selection in certain populations of Drosophila pseudoobscura and Drosophila persimilis. Genetics 33: $158-176$.

Dobzhansky, Th. (1958). Genetics of natural populations. XXVII. The genetic changes in populations of Drosophila pseudoobscura in the American Southwest. Evolution 12: 385-401.

Dobzhansky, Th. (1960). How stable is balanced polymorphism? Proc. Nat. Acad. Sci. USA 46: 41-47.

Dobzhansky, Th. (1962). Rigid vs. flexible chromosomal polymorphisms in Drosophila. Am. Nat. 96: $321-328$.

Dobzhansky, Th. (1963). Genetics of natural populations. XXXIII. A progress report on genetic changes in populations of Drosophila pseudoobscura and Drosophila persimilis in a locality in California. Evolution 17: 333-339.

Dobzhansky, Th. (1971). Evolutionary oscillations in Drosophila pseudoobscura. In: Ecological Genetics and Evolution (Creed, R., ed.). Oxford University Press, London, England, pp. 109-133.

Dobzhansky, Th. and Epling, C. (1944). Contributions to the genetics, taxonomy, and ecology of Drosophila pseudoobscura and its relative. Carnegie Inst. Washington. Publ. 554: 1-183.

Dobzhansky, Th. and Queal, M. (1938). Genetics of natural populations. II. Genic variation in populations of Drosophila pseudoobscura inhabiting isolated mountain ranges. Genetics 23: 463-484.

Dobzhansky, Th., Hunter, A.S., Pavlovsky, O., Spassky, B. and Wallace, B. (1963). Genetics of natural populations. XXXI. Genetics of an isolated marginal population of Drosophila pseudoobscura. Genetics 48: 91-103.

Dobzhansky, Th., Anderson, W.W., Pavlovsky, O., Spassky, B. and Wills, C.J. (1964). Genetic of natural populations. XXXV. A progress report on genetic changes in populations of Drosophila pseudoobscura in the American Southwest. Evolution 18: 164-176.

Dobzhansky, Th., Felix, R., Guzman, J., Levine, L., Olvera, O., Powell, J.R., de la Rosa, M.E. and Salceda, V.M. (1975). Population genetics of Mexican Drosophila. I. Chromosomal variation in natural populations of Drosophila pseudoobscura from Central Mexico. J. Hered. 66: 203-206.

Druger, M. (1962). Selection and body size in Drosophila pseudoobscura at different temperatures. Genetics 47: $209-222$.

Druger, M. (1966). Stability of chromosomal polymorphism in populations of Drosophila pseudoobscura. Heredity 17: 234-238.

Dubinin, N.P. and Tiniakov, G.G. (1945). Seasonal cycles and the concentration of inversions in populations of Drosophila funebris. Am. Nat. 79: 570-572.

Dubinin, N.P. and Tiniakov, G.G. (1946). Natural selection and chromosomal variability in populations of Drosophila funebris. J. Hered. 37: 39-44.

Efron, B. (1982). The Jackknife, the Bootstrap and other Resampling Plans. Society for Industrial \& Applied Mathematics, Philadelphia, PA, USA.

Epling, C., Mitchell, D.F. and Mattoni, R.H.T. (1957). The relation of an inversion system to recombination in wild populations. Evolution 11: 225-247.

Guzman, J., Olvera, O., de la Rosa, M.E. and Salceda, V.M. (1993). Population genetics of Mexican Drosophila. IX: East-west distribution of inversion polymorphism in Drosophila pseudoobscura. Southwest. Nat. $38: 52-55$.

Guzman, J., Levine, L., Olvera, O., de la Rosa, M.E. and Salceda, V.M. (1994). Poblaciones naturales mexicanas de Drosophila pseudoobscura. Memorias del XI Congreso Latino Americano de Genética, Acapulco, Mexico, September 11-15, 1999, pp. 46.

Heuts, M.J. (1948). Adaptive properties of carriers of certain gene arrangements in Drosophila pseudoobscura. Heredity 2: $63-75$.

Kojima, K. and Yarbrough, K.M. (1967). Frequency-dependent selection at the esterase-6 locus in Drosophila melanogaster. Proc. Natl. Acad. Sci. USA 57: 645-649.

Koller, P.C. (1939). Genetics of natural populations. III: Gene arrangements in populations of Drosophila pseudoobscura from contiguous localities. Genetics 24: 22-33.

Lance, G.N. and Williams, W.T. (1967). A general theory of classificatory sorting strategies. I. Hierarchical systems. Comput. J. 9: 373-380.

Landgridge, J. (1962). A genetic and molecular basis for heterosis in Arabidopsis and Drosophila. Am. Nat. 96: 5-27.

Landgridge, J. (1968). Thermal responses of mutant enzymes and temperature limits to growth. Mol. Gen. Genet. 103: $116-126$.

Levene, H., Pavlovsky, O. and Dobzhansky, Th. (1954). Interaction of the adaptive values in polymorphic experimental populations of Drosophila pseudoobscura. Evolution 8: 335-349.

Levene, H., Pavlovsky, O. and Dobzhansky, Th. (1958). Dependence of adaptive values if certain genotypes in Drosophila pseudoobscura on the composition of the gene pool. Evolution 12:18-23.

Levine, L. and Beardmore, J.A. (1959). A study of an experimental Drosophila population in equilibrium. Am. Nat. 93: 35-40.

Levine, L., Olvera, O., Powell, J.R., Rockwell, R.F., de la Rosa, M.E., Salceda, V.M., Anderson, W.W. and Guzman, J. (1995). Studies on Mexican populations of Drosophila pseudoobscura. In: Genetics of Natural Populations. The Continuing Importance of Theodosius Dobzhansky (Levine, L. ed.). Columbia University Press, New York, NY, USA.

Lewontin, R.C. (1958). Studies on heterozygosity and homeostasis. II. Loss of heterosis in a constant environment. Evolution 12: 494-503.

Genetics and Molecular Research 1 (1): 01-24 (2002) www.funpecrp.com.br 
Lewontin, R.C. and Krakauer, C. (1973). Distribution of gene frequencies as a test of the theory of the selective neutrality of polymorphisms. Genetics 74: 175-195.

Li, C.C. and Horvitz, D.G. (1953). Some methods of estimating the inbreeding coefficient. Am. J. Hum. Genet. 5: 107-117.

Mantel, N.H. (1967). The detection of disease clustering and a generalized regression approach. Cancer Res. 27: 209-220.

Mayhew, S.H., Kato, S.K., Ball, F.M. and Epling, C. (1966). Comparative studies of arrangements within and between populations of Drosophila pseudoobscura. Evolution 20: 646-662.

Nei, M. (1972). Genetic distance between populations. Am. Nat. 106: 283-292.

Nei, M. (1977). F-statistics and analysis of gene diversity in subdivided population. Ann. Hum. Genet. 41: 225-233.

Olvera, O., Powell, J.R., de la Rosa, M.E., Salceda, V.M, Gaso, M.I., Guzman, J., Anderson, W.W. and Levine, L. (1979). Population genetics of Mexican Drosophila. VI. Cytogenetic aspects of the inversion polymorphism in Drosophila pseudoobscura. Evolution 33: 381-395.

Olvera, O., Rockwell, R.F., de la Rosa, M.E., Gaso, M.I., Gonzalez, F., Guzman, J. and Levine, L. (1985). Chromosomal and behavioural studies of Mexican Drosophila. III. Inversion polymorphism of D. pseudoobscura. J. Hered. 76 : 258-262.

Parsons, P.A. (1971). Extreme-environment heterosis and genetic loads. Heredity 22: 479-483.

Parsons, P.A. and McKenzie, J.A. (1971). The ecological genetics of Drosophila. Evol. Biol. 4: 325-365.

Pavlovsky, O. and Dobzhansky, Th. (1966). Genetics of natural populations. XXXVII. The coadapted system of chromosomal variants in a population of Drosophila pseudoobscura. Genetics 53: 843-854.

Phaff, H.J., Miller, M.W., Recca, J.A., Shifrine, M. and Mrak, E.M. (1956). Studies on the ecology of Drosophila in the Yosemite region of California. II. Yeasts found in the alimentary canal of Drosophila. Ecology 37: 533-538.

Polanco, M.M., Bustos, E. and Hoenigsberg, H. (1987). Genética de poblaciones en el trópico americano. Algunos mapas del tercer cromosoma de Drosophila pseudoobscura. Evol. Biol. 1: 45-80.

Popadic, A. and Anderson, W.W. (1994). The history of a genetic system. Proc. Natl. Acad. Sci. USA 91: 6819-6823.

Popadic, A., Popadic, D. and Anderson, W.W. (1995). Interchromosomal exchange of genetic information between gene arrangements on the third chromosome of Drosophila pseudoobscura. Mol. Biol. Evol. 12: 938-943.

Powell, J.R. (1992). Inversion polymorphisms in Drosophila pseudoobscura and Drosophila persimilis. In: Drosophila Inversion Polymorphism (Krimbas, C.B. and Powell, J.R., eds.). CRC Press, Boca Raton, FL, USA, pp. 73-126.

Powell, J.R., Dobzhansky, Th., Hook, J.E. and Wistrand, H.E. (1976). Genetics of natural populations. XLII. Further studies on rates of dispersal of Drosophila pseudoobscura and its relatives. Genetics 82: 493-506.

Prakash, S. (1972). Origin of reproductive isolation on the absence of apparent genic differentiation in a geographic isolate of Drosophila pseudoobscura. Genetics 72: 143-155.

Prakash, S. and Lewontin, R.C. (1968). A molecular approach to the study of genic heterozygosity in natural populations. III. Direct evidence of coadaptation in gene arrangements of Drosophila. Proc. Natl. Acad. Sci. USA 59: 398-405.

Prakash, S., Lewontin, R.C. and Hubby, J.L. (1969). A molecular approach to the study of genic heterozygosity in natural populations. IV. Patterns of genic variation in central, marginal and isolated populations of Drosophila pseudoobscura. Genetics 61: 841-858.

Prevosti, A. (1974). La distancia genética entre poblaciones. Miscellanea Alcobé 109-118. Publicacions de la Universitat de Barcelona, Barcelona, Spain.

Prevosti, A., Ocaña, J. and Alonso, G. (1975). Distances between populations of Drosophila subobscura based on chromosomal arrangements. Theor. Appl. Genet. 45: 231-241.

Rasmussen, D.I. (1964). Blood group polymorphism and inbreeding in natural populations of the deer mouse, Peromyscus maniculatus. Evolution 18: 219-229.

Rice, M.C. and O' Brien, S.J. (1980). Genetic variance of laboratory outbred Swiss mice. Nature 283: 157-161.

Robertson, A. and Hill, W.G. (1984). Deviations from Hardy-Weinberg proportions, sampling variances and use in estimation of inbreeding coefficients. Genetics 107: 703-718.

Ruiz-Garcia, M. (1994). Genetic profiles from coat genes of natural Balearic cat populations: an Eastern Mediterranean and North-African origin. Genet. Sel. Evol. 26: 39-64.

Ruiz-García, M. and Alvarez, D. (1997a). Significative evidence of spatial autocorrelation among Drosophila pseudoobscura males and females from Colombia and USA populations using meristic morphological variables. Mendeliana 12: 63-89.

Ruiz-García, M. and Alvarez, D. (1997b). Cat genetic profiles in Catalonia, Spain. Braz. J. Genet. 20: 215-224.

Ruiz-García, M. and Alvarez, D. (2000). Asimetría y dimorfismo sexual interpoblacional en Drosophila pseudoobscura. I. Diferencias en las correlaciones de variables morfológicas. Bol. R. Soc. Esp. Hist. Nat 96: 171-191.

Ruiz-García, M. and Alvarez, D. (2001). Asimetría y dimorfismo sexual interpoblacional en Drosophila pseudoobscura. II. Diferencias en las relaciones espaciales entre variables morfológicas. Bol. R. Soc. Esp. Hist. Nat. 96: 301-324.

Ruiz-Garcia, M., Alvarez, D., Guerrero, J. and Salceda, V.M. (2001). The discovery of new arrangements in the Colombian Drosophila pseudoobscura populations and homogeneity of rearrangement frequencies through a whole year. Ann. Entomol. France 37: 393-404.

Schaeffer, S.W. and Miller, E.L. (1991). Nucleotide sequence analysis of Adh genes estimates the time of geographic isolation of the Bogota population of Drosophila pseudoobscura. Proc. Natl. Acad. Sci. USA 88: 6097-6101.

Schaeffer, S.W. and Miller, E.L. (1992). Estimates of gene flow in Drosophila pseudoobscura determined from nucleotide sequence analysis of the alcohol dehydrogenase region. Genetics 132: 471-480.

Singh, R.S., Lewontin, R.C. and Felton, A.A. (1976). Genetic heterogeneity within electrophoretic "alleles" of xanthine dehydrogenase in Drosophila pseudoobscura. Genetics 84: 609-629.

Genetics and Molecular Research 1 (1): 01-24 (2002) www.funpecrp.com.br 
Smouse, P.E., Long, J.C. and Sokal, R.R. (1986). Multiple regression and correlation extensions of the Mantel's test of matrix correspondence. Syst. Zool. 35: 627-632.

Sokal, R.R. and Michener, C.D. (1958). A statistical method for evaluating systematic relationships. Univ. Kans. Sci. Bull. 38: 1409-1438.

Sphuler, J.N. (1972). Genetic, linguistic, and geographical distances in native North America. In: The Assessment of Population Affinities in Man (Weiner, J.S. and Huizinga, J., eds.). Oxford Universiry Press, Oxford, England, pp. 210-230.

Strickberger, M.W. (1963). Evolution of fitness in experimental populations of Drosophila pseudoobscura. Genetics 53: 843-854.

Strickberger, M.W. and Wills, C.J. (1966). Monthly frequency changes of Drosophila pseudoobscura third chromosome gene arrangements in a California locality. Evolution 20: 592-602.

Wallace, B. (1953). On coadaption in Drosophila. Am. Nat. 87: 343-358.

Wallace, B. (1954). Coadaption and the gene arrangements of Drosophila pseudoobscura. Symp. Genet. of Pop. Structure. Int. Union Biol. Sci. Ser. B 15: 67-94.

Wallace, B. (1959). Influence of genetic systems on geographic distribution. Cold Spring Harbor Symp. Quant. Biol. 24: 193-204.

Weir, B.S. and Cockerham, C.C. (1984). Estimating F-statistics for the analysis of population structure. Evolution 38: $1358-1370$

Wright, S. (1965). The interpretation of population structure by F-statistics with special regard to systems of mating. Evolution 19: 395-420.

Wright, S. and Dobzhansky, Th. (1946). Genetics of natural populations. XII. Experimental reproduction of some of the changes caused by natural selection in certain populations of Drosophila pseudoobscura. Genetics 31: 125-130.

Genetics and Molecular Research 1 (1): 01-24 (2002) www.funpecrp.com.br 